\title{
Selection of UUV Type ROV Equipment and Cooperation System with USV "Edredon" in Protection Tasks of Ports and Critical Objects
}

\section{Zygmunt Kitowski}

The article presents some of the problems associated with the use of an unmanned underwater vehicle type ROV (Remotely Operated Vehicle) to cooperate with the USV (Unmanned Sur-face Vehicle) "Edredon" carrying out tasks related to the perimetric protection of seaports infrastructure and critical objects. The system remote control of the underwater vehicle, requi-res the appropriate structure of the system ensuring the cooperation of both vehicles and the selection of the special apparatus mounted on the ROV. The tasks carried out by the both ve-hicles have a very high impact on the hardware solutions and cooperation of USV with an unmanned underwater vehicle.

\section{KEY WORDS}

$\sim$ USV (Unmanned surface vehicle)

$\sim$ ROV (Remotely underwater vehicle)

$\sim$ Critical infrastructure.

Faculty of Mechanical and Electrical Engineering, Polish Naval Academy, Poland e-mail: z.kitowski@amw.gdynia.pl

doi: $10.7225 /$ toms.v08n02.004

This work is licensed under (cc) BY

\section{INTRODUCTION}

For the protection of critical infrastructure systems in technologically advanced countries, inter alia, unmanned radiocontrolled or programmable (autonomous) surface vehicles are used. The potential of these vehicles increases significantly if they are fitted with a module containing a system for observing and conducting underwater work, which can be controlled by the operator by radio from a distant command control post. During the last dozen years, the awareness of the need to protect critical infrastructures from terrorist attacks has increased considerably. These hazards can occur from the air, the ground and the sea (above or below its surface). Figure 1 shows some of the maritime components of the critical infrastructure..

Traditionally, attention is mainly given to non-underwater threats, which relate to the main part of the resources assigned to the protection of critical infrastructure. As a result, a high level of technology against these threats can be developed, based on access to control, radar, thermal cameras, infrared cameras, etc.

The underwater threat did not have a high priority until

the terrorist attacks of divers that were planned and performed, including by Argentinian divers to British ships in Gibraltar during the Falkland War. As a result of technological deve-lopment, the threat of underwater attack was then small, but it quickly increased in recent ye-ars. The current trend is to ensure total environmental safety, i.e. protection of critical infrastructures, which covers all anticipated threats by creating an integrated marine environmental protection system. 


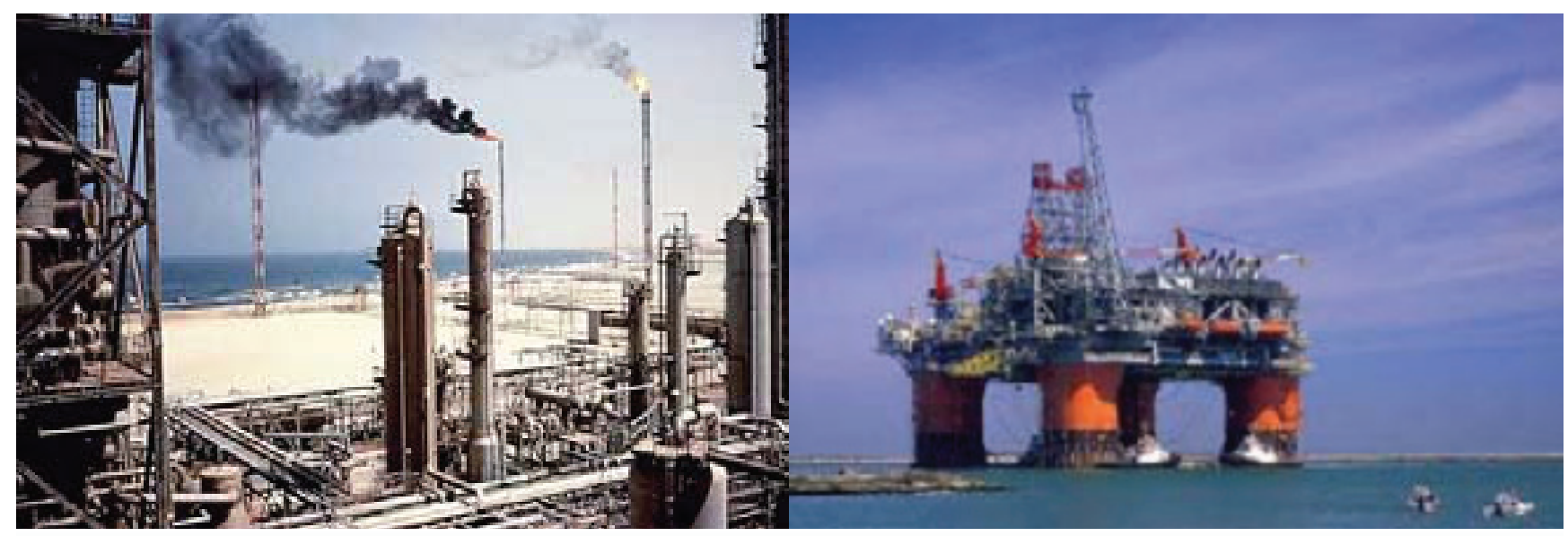

Figure 1.

A few examples of critical infrastructures related to the marine environment (refinery, oil rig), (Source: Materials of projects).

The previous practice proved that unmanned underwater vehicles cooperating with equipment intended for the monitoring of water spaces have a high potential for all kinds of exploratory work. An example of this can be USV equipped with the ROV (ROV - Remotely Underwater Vehicle). This System is designed for any underwater work on both sea and inland waters.
However, there are few USV structural solutions designed to work with the ROV. Most often these are constructions specially designed for this purpose. An example may be an unmanned vehicle Yamaha UMV-H, presented in 2005, which serves as a platform for the unmanned underwater vehicle RDUST-VideoRay (Veers and Bertram, 2006) which are shown in Figure 2.
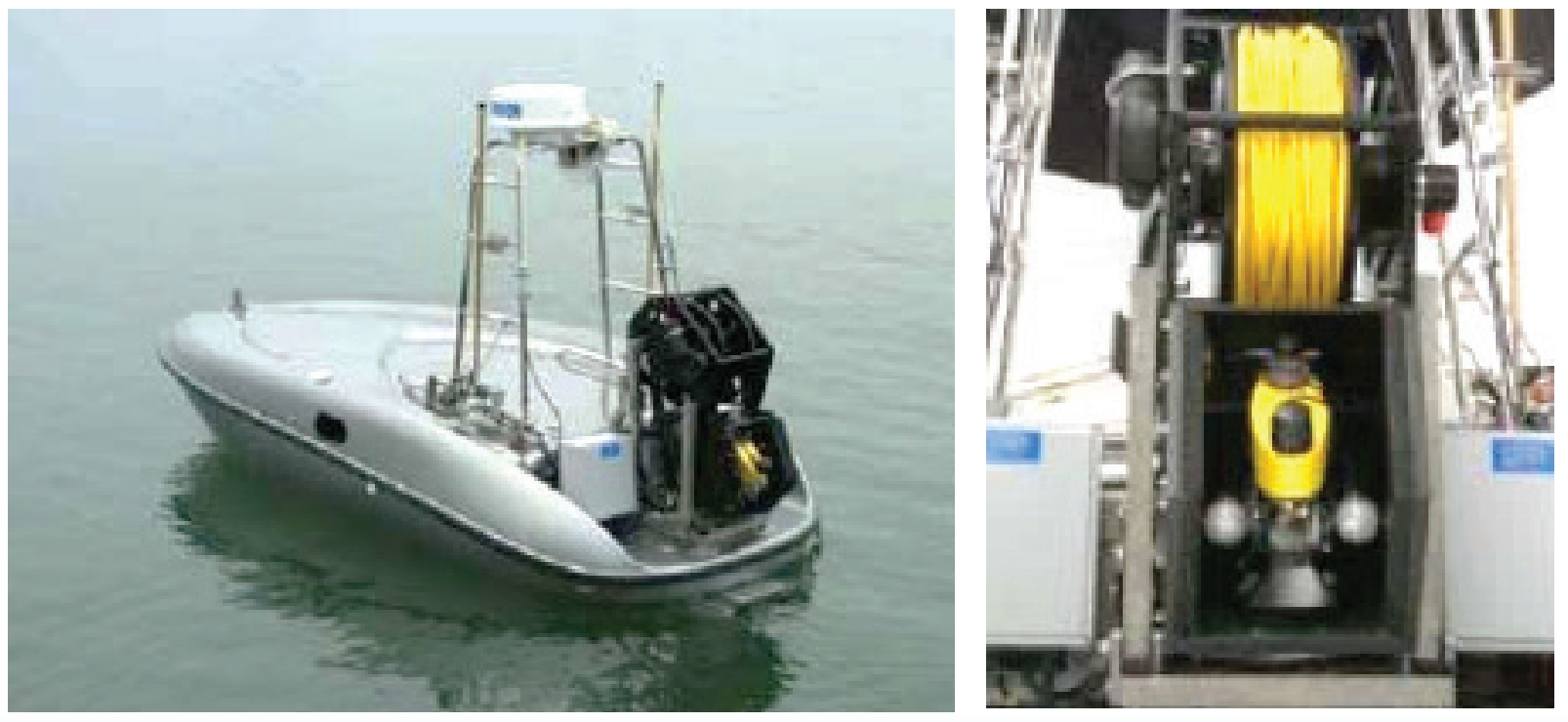

Figure 2.

Yamaha UMV-H and Video Ray Micro-ROV, (Source: Molchan, 2005).

The assumptions for the construction project of the Polish version of the Autonomous Surface Vehicle (ASV) were to develop and build a demonstrator of USV technology and later the ASV under the named "Edredon", performing tasks related to the perimetric protection of infrastructure critical in the framework of which (for the "Edredon" vehicle intended to be used for multivarianeous use by the possibility of equipping it with a variety of modules) is foreseen the use of an unmanned 
underwater vehicle type ROV operating on the USV deck. It was assumed that when decision on the need to perform a mission by an underwater vehicle is undertaken the autonomous mission carried out by the USV "Edredon" will be interrupted and the system will enter into the remote control mode, during which the operator located on a mobile land (or ship) command post will take the control over the ROV vehicle. The tasks of the operator at that time should be: the operation of the ROV from the unmanned underwater vehicle by means of a remote controlled launch and recovery system of the ROV (several concepts of such a system have been developed during the implementation of the project), execution of the set task, and then recovery of the ROV back on board of the USV "Edredon".

\section{THE DESIGN OF THE LAUNCH AND RECOVERY SYSTEM OF THE ROV ON THE USV "EDREDON" BOARD}

The use of such a solution due to the limited space on the stern of USV (Figure 3) turned out to be a very difficult task, that required the solution of a number of structural problems related to the operating conditions of the system, including but not limited to (Materials of projects, 2013):

- The risk of the cable line being screwed into the propeller, resulting from the signifi-cant submersion of the thruster;

- A limited platform surface to mount the launch and recovering system of an underwa-ter vehicle on the USV deck;
- The way of mounting the system structure and taking into account the difference in al-titude the surface of the water, imposing a segmented construction of the entire struc-ture of the equipment for launching and raising of an underwater vehicle on board the surface vehicle;

- The need to use for the construction of light materials, which will not cause a large the vehicle's depth to the stern and the displacement of the metacentric height of the ve-hicle that would cause the of the swimming conditions as well as the performance of the USV;

- Limited possible construction height of the remote launching and recovery system of the vehicle does not cause an increase in the USV centre of gravity and thus manoeu-valability;

- Maximum offset of the system structure of the launching and recovery of the vehicle in the direction of the USV stern exposing the entire unit to continuous contact with water which imposes the use of seawater-resistant materials and equipment;

- The location of the platform on which the system is mounted must not restrict move-ment of the thruster, e.g. its trim;

- The platform must located above the thruster's elevation level, in its extreme top posi-tion.

One of the examined systems for launching/recovering from water of an unmanned type ROV underwater vehi-cle on board the USV "Edredon", is shown in Figure 3.

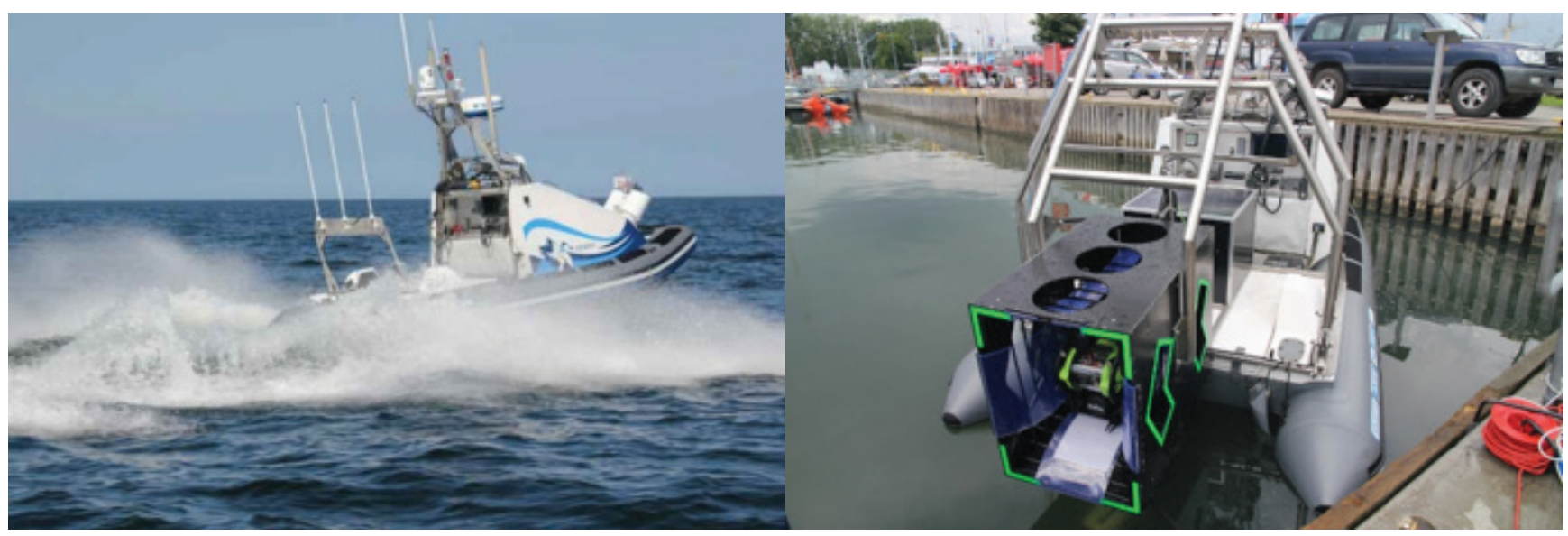

Figure 3.

Platform stern - the location of the launch and recovery system on the USV board (Source: Materials of projects).

An important problem that appeared during the design of the system became the choice of the appropriate ROV type submarine and equipping it with apparatus for the realization of tasks related to the perimetric protection of critical objects. As the underwater vehicle is intended to carry out underwater inspections in close proximity from the autonomous surface vehicle "Edredon", the technical assumptions are formulated based on an analysis of the possible tasks. Concerning the work of the ROV and its operational capacities such as: mass, dimensions, immersion, equipment in sensors, etc. For the design of the system, among others (materials of projects and Olejnik.A, 2012): 
The possibility of fast launching and recovery on the board of USV "Edredon" (time of launching the garage with the ROV or the time of its lifting on board USV) should not exceed 60s.,

- The weight of the ROV in the air should not exceed $20 \mathrm{~kg}$,

- The geometric dimensions should be in a rectangular wall with a volume of up to $1 \mathrm{~m}^{3}$,

- The vehicle should be capable of operating in the Baltic Sea environment at depths $50 \mathrm{~m}$,

- The underwater vehicle should be equipped with sensors to detect contaminations chemical and biological

- The vehicle has the ability to determine its own position, e.g. for the purpose of determining the location of contamination,

- Detection and/or classification of underwater objects is possible.
However, the most important element was the transmission of images from cameras and sensors mounted on the ROV to the mobile land (or ship) command post and the ROV's remote control.

\section{THE EQUIPMENT OF THE UNDERWATER VEHICLE IN SENSORS AND DEVICES EXTENDING THE OPERATING POSSIBILITIES OF THE VEHICLE.}

Based on the analysis of the vehicles, available on the market, a underwater vehicle LBV200-4 type ROV of the American company Teledyne SeaBotix Company was selected (Figure 4).
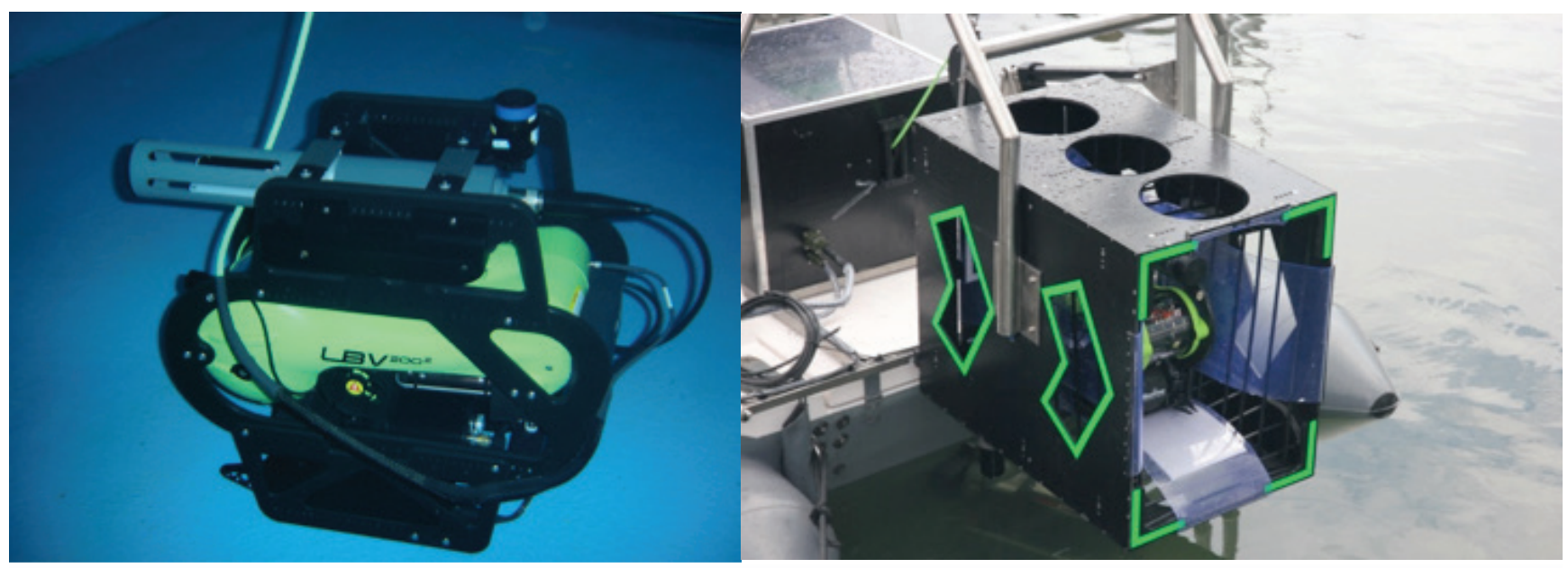

Figure 4.

Remote controlled underwater vehicle LBV200-4 mounted on the board of USV "Edredon" (Source: Materials of projects).

In order to ensure that the vehicle LBV200-4 is carried out under water under the hydrome-teorological conditions, several additional sensors and devices extending the operating capabilities of the vehicle have been selected. Due to the possible use of the ROV vehicle to coope-rate with the USV and to perform the widest possible spectrum of tasks, the vehicle was addi-tionally equipped with [Materials of projects]:

- $\quad$ Rear camera supporting the operator with the launch and recovery system control,

- Manipulator robot with three-jaw gripper;

- Additional Outdoor Lighting

- BlueView sonar with a viewing angle of $130^{\circ}$,

- Subwater Positioning System Tritech MicronNav USBL;

- $\quad$ Probe for measuring the physico-chemical parameters of marine pollution.
The task of the rear camera is to assist the operator of the ROV during the operation of its launching from and recovery on board the USV "Edredon" to prevent the misalignment of the cable line in the water and on the drum (Figure 5).

The three-jaw gripper-the (manipulator - Figure 5), in addition to the possibility of carrying out simple inspection work, ensures the transfer of objects found on the USV.

One of the tasks carried out by the unmanned surface vehicle "Edredon" is the detection of chemical and biological contamination. Therefore, the probe for measuring marine environ-ment parameters is, from the point of realization of tasks set in the project, one of the most important components installed on the underwater vehicle. During the selection of the subma-rine LBV200-4 the attention was also paid to the possibility of equipping the vehicle with a water quality probe, 


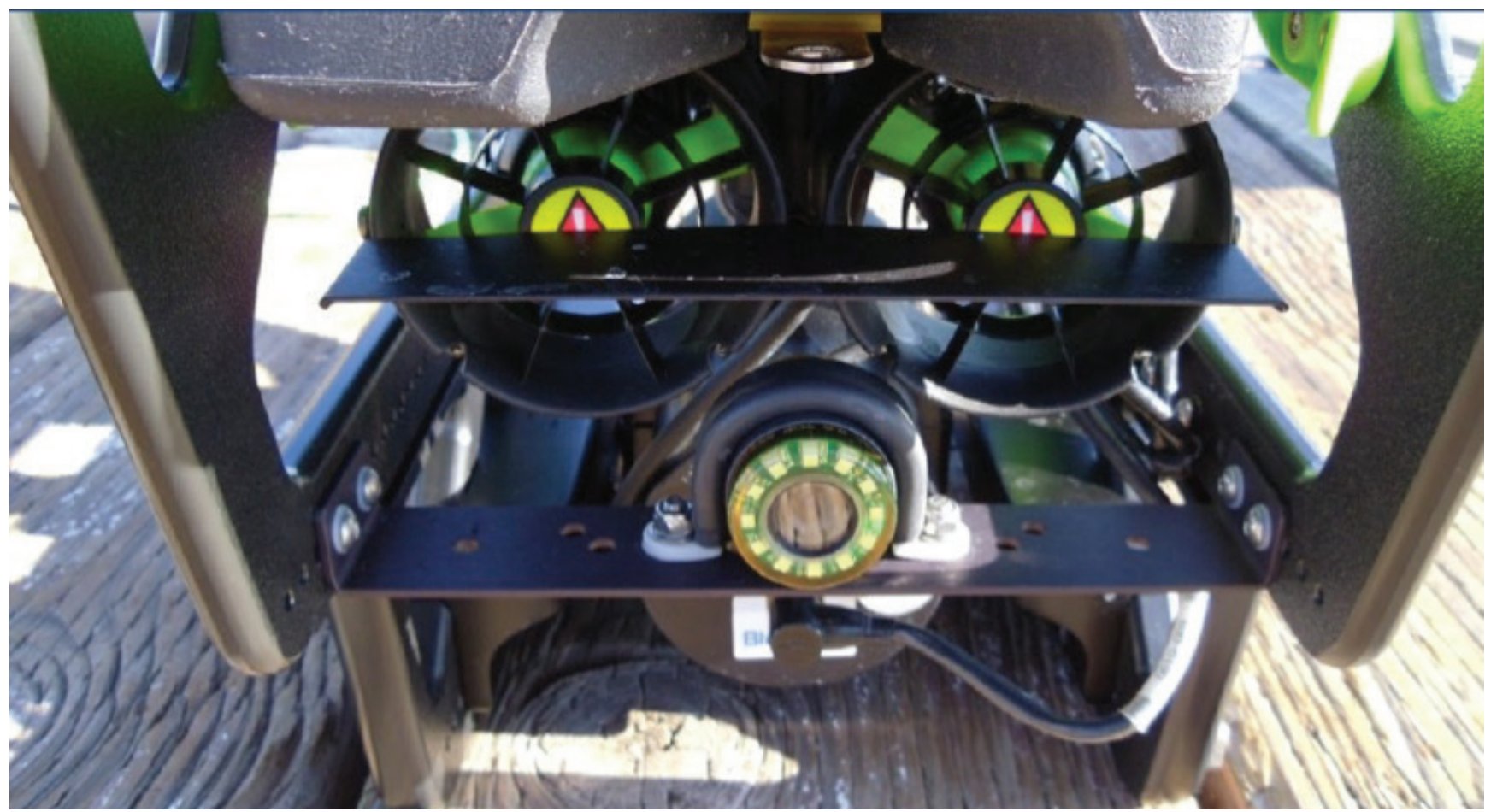

Figure 5.

Rear camera of the ROV with annular backlighting, (Source: Materials of projects).

which is able to measure and send to the command center, via the "Edre-dona" wireless communication systems, a dozen water quality parameters. For the measure-ment of the physicochemical contamination of the marine environment, the YSI type 6820 probe (Figure 6), which was integrated into the vehicle, was used to transmit the RS-232 se-rial link backup data.

The available sensor optical sensors detect and measu -re the following components in the water:

- Dissolved oxygen;

- Blue-green algae;

- Chlorophyll;

- Water turbidity;

- Rodamine.

The following water parameters can also be measured using the 6820 sonde:

- Temperature;

- Conductivity;

- Salinity;

- Proper conductivity;

- $\quad \mathrm{PH}, \mathrm{ORP}, \mathrm{TDS}$ ratios;

- Water flow;

The content of nitrate nitrogen, ammonia/ammonium nitrogen, chloride (ISE).

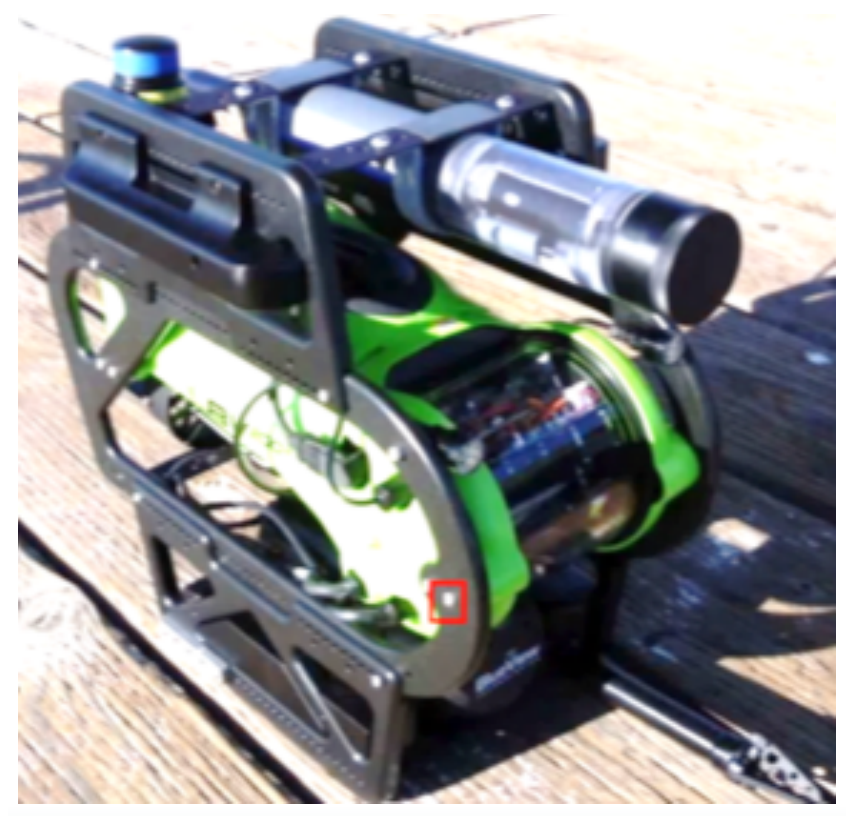

Figure 6.

Water quality sonde and manipulator of the ROV, (Source: http://www.ysi.com/products.php, http://www.seabotix. com/products/lbv200-4.htm). 
The sonde transmits signals to the ROV Central Unit. The data from the sonde, as well as the sonar data and the underwater positioning system, are converted into an optical signal transmitted to the cable line drum. There, they are converted to an analog signal that is transmitted to the Central Control Unit of the ICC (Integrated Control Console) or a PC-class computer with built-in software to receive this data.

The unmanned surface vehicle "Edredon" with the LBV2004 underwater vehicle is to per-form various tasks in the Baltic Sea area, in particular the Gulf of Gdansk. Due to the poor visibility of the Baltic Sea water (ranging from 4 to $10 \mathrm{~m}$, deteriorating as the depth increases) there is a need to install additional lighting on the vehicle. The project uses a set consisting of two LED heads, which gives the light flux of 2860 lumen (Figure 7) with the basic illumina-tion.

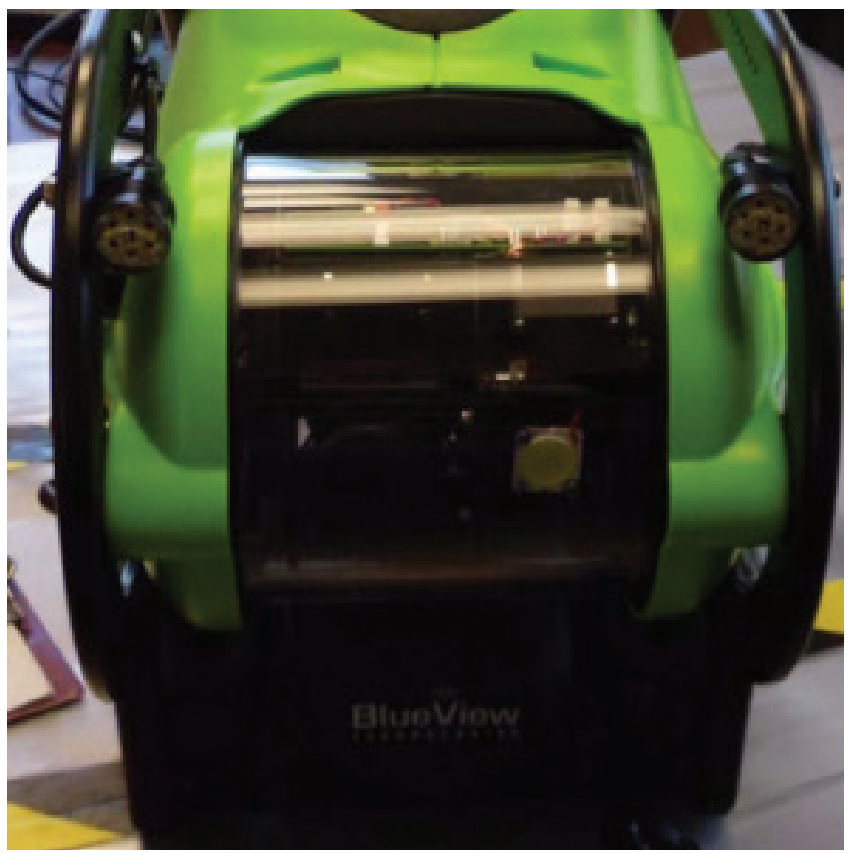

Figure 7.

Additional Outdoor LED Lighting (Source: http://www. seabotix.com/products/lbv200-4.htm).

Another additional device is the sonar. The project decided to choose BlueView's high-performance 2D sonar with a viewing angle of $130^{\circ}$ (Figure 8).

The sonar is placed at the bottom of the vehicle, on a specially prepared platform integrated with the backbone of the ROV vehicle. The sonar image is transmitted using RS-232 serial transmission. The transmission from the socket is converted to optical signals, so that they can be transmitted using a fibre optic cable to the converter located in the cable line drum. There, the optical signal is converted to the transmission with a twistedpair computer cable and for-warded to the ICC (Integrate Control Console).

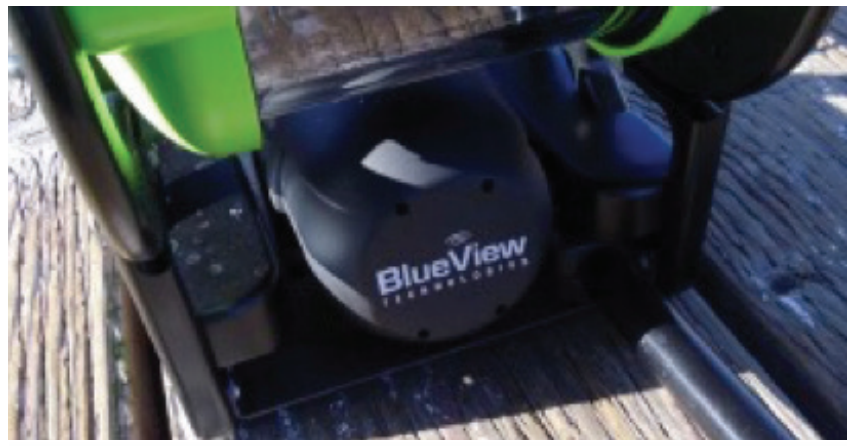

Figure 8.

Sonar 2D Blueview P900 (Source: https://www.

ashteadtechnology.com/product/teledyne-blueview-p900130-2d-forward-looking-imaging-sonar).

The underwater positioning system is an important device for increasing the ability to operate the underwater vehicle. It allows to determine the position of the underwater vehicle in regard to the surface vehicle, record the trajectory of its movement, and determine the position of possible objects, e.g. Possible sources of chemical and biological contamination. SeaBotix offers positioning System Tritech International MicronNav (Figure 9). The System has a ran-ge of $500 \mathrm{~m}$, positioning accuracy \pm 0.2 $\mathrm{m}$ and bearing accuracy $\pm 3^{\circ}$. The positioning speed is from 0.5 to 10 s. This System consists of:

- MicronNav interface,

- USBL Transducer,

- MicronNav Underwater unit.

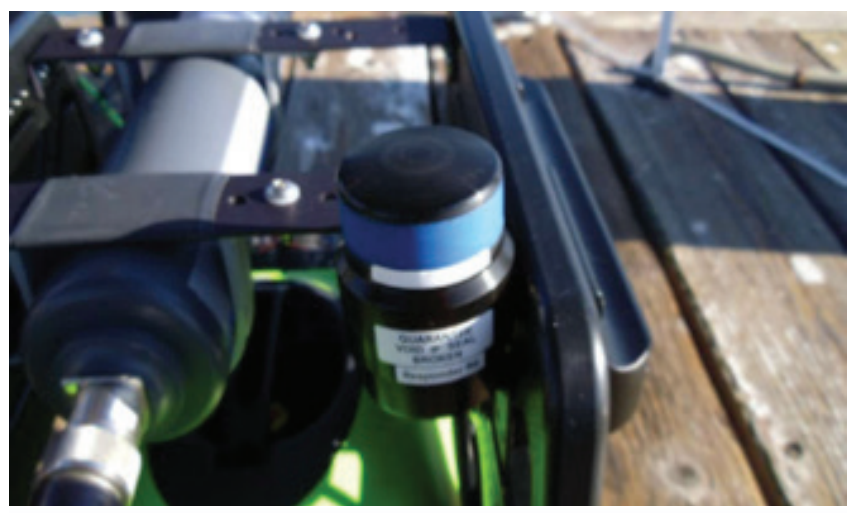

Figure 9.

Underwater Positioning System Tritech International MicronNav (Source: Materials of projects). 


\section{CONCLUSSIONS}

Based on the accepted tactics of the vehicle use, and its measured real dimensions and we-ights, as well as the specified possible locations for the positioning and fastening of the elements of the launching system on board of the unmanned USV vehicle, the choice of the way of launching of the ROV was made (3 concepts were developed - preliminary projects for launching and recovering of the ROV on board of the USV "Edredon") (Materials of projects, 2013), the positioning of the launching system, and the location of the transducer for under-water navigation. It was assumed that the ROV will be transported on the board, and then lowered, and recovered from the water in a container, the so-called underwater garage. The vehicle should not be able to move when it enters (retracting) the garage, and the garage itself should be a construction that protects the ROV from mechanical damage during transport to the area of operation and at the time of leaving and particularly in the surface wave impact zone.

Trials and tests of the launching system of a ROV-type submarine, under laboratory and real-life conditions, have demonstrated its correct operation. It turned out, however, that the desi-gned construction of the ROV garage is too heavy for the tested surface vehicle "Edredon. The ROV operator was advised to observe the reciprocal positioning of the vehicle and the garage with a rear-view camera mounted on the ROV when manoeuvring the vehicle for its garages after the mission was performed, and on the basis of these observations corrected the operation of the winch cable line vehicle. The study also verified the interoperability of the system mechanisms with the USV platform design and a cant test. The results of the cant test confirmed the design assumptions given to the launching system and its minor influence on the stability of the "Edredon" USV unit after its installation on board (Materials of projects, 2013)].

The construction of the garage requires further work related to reducing its weight e.g. by changing the applied construction materials.

\section{REFERENCES}

Materials development project No R00 0106 12, 2013. Integrated planning system of and mo-nitoring of marine ports and critical objects based on the autonomous unmanned units. Gdańsk, 2010-2013.

Molchan, M., 2005.The Role of Micro-ROVs in Maritime Safety and Security, Marine Scien-ces, p.38

Olejnik, A., 2012. Activity tactics of an unmanned underwater remotely operated vehicle from deck of an unmanned surface vehicle in underwater inspection tasks. Polish Hyperbaric Research, 3(40), pp.23-56.

Veers, J. \& Volker, B., 2006. Development of the USV Multi-Mission Surface Vehicle III, 5th Int. Conf. Computer and IT Application in the Maritime Industries (COMPIT), Lei Den, pp.345-355.

Volker, B., 2019.Unmanned Surface Vehicles - A Survey. ENSIETA, Brest, France. 